\title{
Facilitators of mHealth Implementation Program
}

\section{Tukaram Narayan Khandade*}

Department of Health informatics, IIHMR University, Jaipur, Rajasthan, India

\begin{abstract}
Healthcare applications of mobile phones are steadily gaining popularity over last few years. With the increasing penetration of mobile networks in remote rural villages in India, mobile phones are becoming an important tool for enhancing doctor-patient communication. The mobile technology is increasingly enhancing functionalities of handheld devices, smart phones and PDAs, which are potentially replacing the use of PC, based alternatives while supporting mobility needs of patients and medical practitioners.

The study looks at the facilitators of them Health program (mobile based reporting by Front Line Workers in public health) in Saharsa district of Bihar state in India. Data was collected in July 2017. 109 FLWs were contacted for the study.

The results tell us that education plays an important role in mobile based reporting system. Age of the respondents does not relate to the mobile phone based reporting system. The willingness to use the mobile phone for reporting is at $80 \%$ taken overall. Across age group the worry regarding the lack of hard copy of data is very less and stood at overall $40 \%$ level. Respondents from all age group indicated that the timing of the reporting was appropriate and it stood at $85 \%$.

The logistic regression tells us that appropriateness of the reporting time increases by 4.1 times, when the FLW receives the needed service from the mobile platform. Effectiveness of the work of the FLW would decrease by $89 \%$ if she is worried about the lack of hard copy of the data. Willingness to continue the mobile phone for reporting would increase by 4.34 times, for those FLW, who are recommending the program to continue. Appropriateness of the reporting time increase by 5.26 times, when the FLW recommends continuing the program.

The mobile based reporting system generates the real time data. The same can be used to create dashboards for the Sustainable Development Goals (SDG). The tracking can be created at state or national level. Even the district level dashboards can be created. The data from the front line workers will get used on real time basis. The action on certain aspect of the program can be very quick.
\end{abstract}

Keywords: Front line worker; mHealth; Facilitator; Public health

\section{Introduction}

Jeffrey Sachs, the Director of the Earth Institute, has suggested that 'Mobile phones and wireless internet end isolation, and will therefore prove to be the most transformative technology of economic development of our time' [1]. Mobile technology stands out as more robust and sustainable option as compared to PC based telemedicine in remote rural villages in India, with the increasing penetration and rising transmission capabilities of mobile networks. However, the technology becomes a powerful transformational tool if it is applied as an enabler of a synergistic system.

Healthcare applications of mobile phones are steadily gaining popularity over last few years $[2,3]$. With the increasing penetration of mobile networks in remote rural villages in India, mobile phones are becoming an important tool for enhancing doctor-patient communication [4]. The mobile technology is increasingly enhancing functionalities of handheld devices, smart phones and PDAs, which are potentially replacing the use of PC based alternatives while supporting mobility needs of patients and medical practitioners [5,6]. With these advantages it is increasingly becoming possible to create innovative applications for developing countries that can shift the paradigm of delivering services and resolve problems plaguing the healthcare systems [7].

Most commonly, community health workers use mobile technology to collect field-based health data, receive alerts and reminders, facilitate health education sessions, and conduct person-to-person communication [8]. In a systematic review done by Aranda-Jan et al. on the mHealth studies conducted in Africa, mHealth projects demonstrated positive health-related outcomes. But their success was based on the on the accessibility, acceptance and low-cost of the technology, effective adaptation to local contexts, strong stakeholder collaboration, and government involvement. She also discussed some of the threats faced by the mHealth system, dependency on funding, unclear healthcare system responsibilities, unreliable infrastructure and lack of evidence on cost-effectiveness challenge their implementation [9]. In a study conducted in Aceh Besar by Chib A, findings were confirming that the mobile phone has proven to be an effective and efficient device for facilitating communication and allowing speedier emergency responses. The mHealth system aids in gathering and disseminating health-related information to midwives, who in turn convey this knowledge to the community [10].

Participatory evaluation of mobile phone intervention for community health workers in Malawi reported increased selfconfidence of the community health workers and greater trust by their communities in them [11]. In study of assessing the impact of mHealth

${ }^{*}$ Corresponding author: Tukaram Narayan Khandade, Department of Health informatics, IIHMR University, Jaipur, Rajasthan, India, Tel: 9985100001; E-mail: tkhandade@gmail.com

Received January 27, 2018; Accepted February 02, 2018; Published February 06, 2018

Citation: Khandade TN (2018) Facilitators of mHealth Implementation Program. J Health Med Informat 9: 302. doi: 10.4172/2157-7420.1000302

Copyright: @ 2018 Khandade TN. This is an open-access article distributed under the terms of the Creative Commons Attribution License, which permits unrestricted use, distribution, and reproduction in any medium, provided the original author and source are credited. 
interventions in low and middle income countries growing evidence was found for the efficacy of mHealth intervention in LMIC. This efficacy was particularly found in treatment adherence, appointment compliance, data gathering and developing support networks for health workers. More work needs to be done on their quantity and quality aspect [12]. A formative evaluation of mHealth intervention in rural India found that the mHealth for ASHAs is found to be largely acceptable and feasible. The mHealth is useful when used as job aid in scheduling the health care services and opening behaviour change communication discussions with the community [13]. Studies that evaluated program outcomes provided some evidence that mobile tools help community health workers to improve the quality of care provided, efficiency of services, and capacity for program monitoring.

Facilitator is the factors that ease the process of implementation during the project. Whereas the barriers will make the process of implementation more complex, hence demanding more energy and more resources. The factors can be related to human resources, finances, technology and acceptance by beneficiaries. This paper assesses the factors that were proven as to facilitators of the mHealth program implementation in rural India, in state of Bihar. The study was conducted in Saharsa district of Bihar. Front line health workers were interviewed for the use of mobile phone for reporting [14].

\section{Methods}

In this study, the FLW was interviewed for their experience with the mobile phone-based application during the project phase. The Frontline workers Anganwadi Worker (AWW) and Accredited Social Health Activist (ASHA the AWW are posted at the village level, they are preschool teachers at the village level. But they look after the community mobilization for $\mathrm{MCH}$ services. ASHA is voluntary worker looking after 1000 population. She supports the community mobilization for all health programs. In total there are $403 \mathrm{FLW}$ working in the pilot blocks. Among them, 128 are ASHA and 148 are AWW. We used population proportionate to Size method to arrive at the sample for each group. The proportion of ASHA is 0.8 and AWW is 0.2 in the total of 403 . The same rates are applied to sample size of 120. It provides the sample for ASHA at 60 and for AWW at 60.

The study contacted 120 Front Line Worker (FLWs) and asked questions about their experience of the program. All of the FLW were using mobile phones for their personal use.

The sample size of the study is calculated by formula given below.

Where - n (Sample size), Z (Confidence level), P (Prevalence), d (Deviation from prevalence)

DEFF (Design effect).

$$
n=\frac{Z_{\alpha / 2}^{2} P(1-P)}{d^{2}} * D E F F
$$

There are three types of respondents Front Line Health Workers, beneficiaries and project officials. The sample size for each of category of respondents is as follows:

1) Front Line Health Workers- 120

2) Beneficiaries-233

The study area is two selected blocks of Sahrsa district in Bihar state in India.

\section{Selection of front line health workers}

For calculating the sample of FLW the value of $\mathrm{Z}$ is taken as 1.96 and $\mathrm{P}$ is at $50 \%$ with $\mathrm{d}$ at $10 \%$. The design effect is taken as 1 because the sampling would be done by Simple Random Sampling method. This is possible, as the list of ASHA and AWW is available with the block level health office. By the formula, the sample size comes to 96 . The nonresponse at $20 \%$ is taken into consideration to arrive at the final sample size of 116, we approximated it to 120 .

\section{Selection of beneficiaries}

For calculating the sample for the Beneficiary level the value of $\mathrm{Z}$ is taken as 1.96 and $\mathrm{P}$ is at $50 \%$ with $\mathrm{d}$ at $10 \%$. The design effect is taken as 2. This is because the two-stage cluster sampling is used.

The cluster is defined as the working area of FLW. It is 106 as per the above sampling. Now in each area beneficiaries are to be contacted for an interview. Using the formula in the sample size comes to 212 . The non-response at $10 \%$ is taken into consideration to arrive at the final sample size of 233. So in 106 clusters, we need 2 beneficiaries per cluster to cover the sample. To achieve the 233 number, the study will cover 3 respondents in 2 clusters. Every FLW has a list of the beneficiary of their area, with them. It will be used for choosing the respondent. Simple random sampling will be used at this level.

The beneficiary is defined as the woman residing in the given FLW working area. She should have received the services from the FLW. The most important is that the FLW had started using the mobile phone for reporting.

Beneficiaries from the ASHA area and officials looking after project were contacted for the interview and responses were collected from them. The data was collected using two different study tools. The questionnaire for frontline health worker was used to collect the information on background characteristic, project implementation experience. Schedule for beneficiary was used to collect the experience in receiving the service from a mobile user FLW.

The questionnaire was developed for the study, is comprised of nominal and ordinal questions. Likert scale is also used to get the opinion of the FLW and officials. The questionnaire for FLW was divided into sections as informed consent, facility identification, background characteristic, project implementation learning and work satisfaction. For FLW the questionnaire is structured one and for officials, we used a checklist.

\section{Results}

The Front Line workers used the mobile phone for reporting. The timeliness of their reporting is crucial. The study speaks about the appropriateness of reporting time, which implies the real time data entry by the FLW on the mobile phone. After entering the data the FLW can see the reports and related analysis, due list and reminders for the due services on the mobile phones. This kind of data received from the mobile platform is needed by the FLW. By using this data the FLW is able to do her work more effectively and achieve low immunization dropout rates and other indicators.

When reporting on mobile phone FLW will not have hard copy of the data, sometime that may worry her. As she needs to see the cumulative and comparative reports of her facility and her service area. These reports will be available on her mobile phone. By using this online dashboard she can manage her work in a good manner. Hence, they are willing to use the mobile phone reporting.

The sample coverage for the FLW in this study is $91 \%$, received responses from 109 respondents against the sample size of 120 . For ASHA the sample coverage is $92 \%$, that 55 ASHA respondents out of 60 and for AWW it is $90 \%, 54 \mathrm{AWW}$ respondents out of 60 . 
In terms of education the $58 \%$, that is 63 out 109 are educated till middle level schooling, 23\%, 25 out of 109 are educated till secondary level school and same are trained in higher secondary school.

From Table 1 it is clear that the willingness to use the mobile phone for reporting is very strong.

While reporting on mobile phone, the FLW will lack the hard copy of the data. This worried about $64 \%$ of FLW, who are educated till secondary level $\left(10^{\text {th }}\right.$ standard). This is suggestive that this group is not comfortable with online data retrieval using mobile phone. Whereas the FLW educated till graduate and above level are only $17 \%$ of them are worried. It is clearly showing the comfort with data retrieval from mobile phone. So education plays an important role in mobile based reporting system. Overall $85 \%$ of FLW stated that the timing of the reporting was appropriate.

From Table 2 it is clear that the age of the respondents does not relate to the mobile phone based reporting system. The willingness to use the mobile phone for reporting is at $80 \%$ taken overall. Across age group the worry regarding the lack of hard copy of data is very less and stood at overall $40 \%$ level. Respondents from all age group indicated that the timing of the reporting was appropriate and it stood at $85 \%$. Further the analysis was conducted on State 13.1, table and logistic regression was done. Appropriateness of the reporting time increases by 4.1 times, when the FLW receives the needed service from the mobile platform (Table 3 ).

The mobile platform can provide automated reminders, list of the beneficiaries for which the health services are due in coming month, audio visual jobs aids. When the FLW receives these services as per her need, then she is 4.1 time more likely to report the data on real time (Just after the provision of services) through her mobile phone.

\begin{tabular}{|c|c|c|c|c|c|c|}
\hline Education level & \multicolumn{2}{|c|}{$\begin{array}{c}\text { willingness to } \\
\text { continue the } \\
\text { mobile phone for } \\
\text { reporting }\end{array}$} & \multicolumn{2}{|c|}{$\begin{array}{c}\text { worried about } \\
\text { lack of hard copy } \\
\text { of data }\end{array}$} & \multicolumn{2}{|c|}{$\begin{array}{c}\text { Timing of the } \\
\text { reporting was } \\
\text { appropriate }\end{array}$} \\
\hline Yes & Total $(\mathrm{n})$ & Yes & Total (n) & Yes & Total (n) \\
\hline Middle & $79 \%$ & 63 & $33 \%$ & 63 & $84 \%$ & 63 \\
\hline Secondary & $80 \%$ & 25 & $64 \%$ & 25 & $100 \%$ & 25 \\
\hline Higher Secondary & $87 \%$ & 15 & $40 \%$ & 15 & $67 \%$ & 15 \\
\hline $\begin{array}{c}\text { Graduates and } \\
\text { above }\end{array}$ & $67 \%$ & 6 & $17 \%$ & 6 & $83 \%$ & 6 \\
\hline Total & $80 \%$ & 109 & $40 \%$ & 109 & $85 \%$ & 109 \\
\hline
\end{tabular}

Table 1: Crosstab Education of the respondents and mobile phone use.

\begin{tabular}{|c|c|c|c|c|c|c|}
\hline $\begin{array}{c}\text { Age of } \\
\text { respondents }\end{array}$ & \multicolumn{2}{|c|}{$\begin{array}{c}\text { willing to continue } \\
\text { the mobile phone }\end{array}$} & $\begin{array}{c}\text { worried about lack } \\
\text { of hard copy of } \\
\text { data }\end{array}$ & \multicolumn{2}{|c|}{$\begin{array}{c}\text { timing of the } \\
\text { reporting } \\
\text { appropriate }\end{array}$} \\
\hline & Yes & Total $(n)$ & Yes & Total $(n)$ & Yes & Total $(n)$ \\
\hline $27 \mathrm{Yr}$ to $30 \mathrm{Yr}$ & $92 \%$ & 13 & $31 \%$ & 13 & $85 \%$ & 13 \\
\hline $31 \mathrm{Yr}$ to $35 \mathrm{Yr}$ & $91 \%$ & 33 & $42 \%$ & 33 & $85 \%$ & 33 \\
\hline $36 \mathrm{Yr}$ to $40 \mathrm{Yr}$ & $60 \%$ & 25 & $44 \%$ & 25 & $72 \%$ & 25 \\
\hline $41 \mathrm{Yr}$ to $45 \mathrm{Yr}$ & $76 \%$ & 25 & $44 \%$ & 25 & $100 \%$ & 25 \\
\hline $46 \mathrm{Yr}$ to $50 \mathrm{Yr}$ & $83 \%$ & 12 & $33 \%$ & 12 & $83 \%$ & 12 \\
\hline $51 \mathrm{Yr}$ to $55 \mathrm{Yr}$ & $100 \%$ & 1 & $0 \%$ & 1 & $100 \%$ & 1 \\
\hline Total & $80 \%$ & 109 & $40 \%$ & 109 & $85 \%$ & 109 \\
\hline
\end{tabular}

Table 2: Crosstab Age of the respondents and mobile phone use.

\section{\begin{tabular}{|l|l|l|l|}
\hline Reference category & Outcome variable & Odds ratio & $\mathbf{P}$ value \\
\hline
\end{tabular}}

\begin{tabular}{|c|c|c|c|}
\hline FLW receives the needed service & $\begin{array}{c}\text { Appropriateness of the } \\
\text { from the mobile platform }\end{array}$ & 0.2415 & 0.047
\end{tabular} from the mobile platform.

Table 3: Logistic regression 1.

Effectiveness of the work of the FLW would decrease by $89 \%$ if she is worried about the lack of hard copy of the data (Table 4).

When a FLW uses the mobile phone for her reporting, then she would not have the registers with her, as the data is digitized at the point of its generation. So if she needs to look at the trend or last month data then she should use her mobile phone and its feature to retrieve that data. This sometimes may cause worry in those FLW who are not comfortable with online data retrieving. So if she is worried, her focus on service delivery will be reduced, hence decreasing the desired effect of prevention of disease or cure of disease by $89 \%$. This is likely to happen as she will be thinking of the record of the service, instead of the service delivery itself.

Willingness to continue the mobile phone for reporting would increase by 4.34 times, for those FLW, who are recommending the program to continue (Table 5).

Appropriateness of the reporting time increases by 5.26 times, when the FLW recommends continuing the program.

If a FLW finds the mHealth program to be beneficial to her, she will recommend it and those will be FLW who are willing to use the mobile phone for reporting. The same FLW is 5.26 times more likely to find the timing of the reporting appropriate with her work culture.

\section{Discussion}

Mobile phones provide an incredible opportunity to vastly improve the quantity, quality and service that community health workers provide, particularly in countries with very limited resources for health worker training and supervision. Study conducted in Ghana in $\mathrm{MoTeCH}$ (Mobile Technology for Community Health Workers) context brought out a beautiful concept of women empowerment, as some women have commented that the messages from the mobile phone have empowered them to insist on accessing health services in ways that are sometimes discouraged by traditional beliefs and elder relatives [15]. These results of this study corroborate the results found in the other studies. In this study the front line workers feel more credible when they carry their mobile with them and conduct a communication session with the use of audio-video content stored on the mobile phone. Community health workers have used mobile tools to advance a broad range of health aims throughout the globe, particularly maternal and child health, HIV/AIDS, and sexual and reproductive health. Most commonly, community health workers use mobile technology to collect field-based health data, receive alerts and reminders, facilitate health education sessions, and conduct person-toperson communication [16].

The Expansion of Mobile technology offers considerable potential to improve health care. The utilization of smartphones and tablets opens up communications, information access, and service delivery.

\begin{tabular}{|c|c|c|c|}
\hline $\begin{array}{c}\text { Reference category } \\
\begin{array}{c}\text { Effectiveness of the work } \\
\text { of the FLW }\end{array}\end{array}$ & $\begin{array}{c}\text { Outcome variable } \\
\text { Worried about the lack of } \\
\text { hard copy of the data. }\end{array}$ & Odds ratio & P value \\
\hline \multicolumn{3}{|c|}{ Table 4: Logistic regression 2. } \\
\hline Reference category & $\begin{array}{c}\text { Outcome variable } \\
\text { FLW recommends } \\
\text { continuing the program. }\end{array}$ & $\begin{array}{c}\text { Willingness to continue the } \\
\text { mobile phone for reporting }\end{array}$ & 0.041 \\
\hline & $\begin{array}{c}\text { Appropriateness of the } \\
\text { reporting time }\end{array}$ & 0.1954 & 0.011 \\
\hline
\end{tabular}

Table 5: Logistic regression 3. 
Their emergence empowers patients, health care providers, and entrepreneurs and offers new options to make transactions and access expertise. In a number of different ways, this technology is poised to alter how health care is delivered, the quality of the patient experience, and the cost of health care [17].

Rapid adoption of mobile telephony in rural India and absence of other information and communication technology media have prompted the social sector to exploit mobile communication as a dependable and effective ICT media. Intervention studies and projects in low resource settings of developing countries have underlined multiple roles and effectiveness of mobile communications in the health sector. In particular, the delivery function of public health programs can be improved by using prompts and reminders through SMS and voice calls for the health workers. In the state of Orissa in India, for example, mobile videos were instrumental in improving the quality of counselling among the community health workers. These messages have been successfully utilized in assisting the beneficiaries achieve their health behaviour goals. Improvement in quality and timeliness of data can help the health system dynamically manage the delivery and promotion functions. Despite these promises, certain technological and programmatic challenges impede the adoption of mHealth in a large scale across the health system. There are many areas of research and development opportunities for organizations to collaborate [18].

Mobile health (mHealth) has a great potential to deliver life-saving information even in the most remote and resource poor settings in developing countries and can serve as an access point of national surveillance systems. Additionally, it offers an effective contribution to public health initiatives in support of achieving the health related Millennium Development Goals (MDGs) while being economical, effective and sustainable. The mobile based reporting system generates the real time data. The same can be used to create dashboards for the Sustainable Development Goals (SDG). The tracking can be created at state or national level. Even the district level dashboards can be created. The data from the front line workers will get used on real time basis. The action on certain aspect of the program can be very quick $[19,20]$.

\section{References}

1. https://www.theguardian.com/uk/commentisfree

2. Blake $\mathrm{H}$ (2008) Innovation in practice: mobile phone technology in patient care Br J Community Nurs 13: 2-5.

3. Yip W (2006) Use of Mobile Wireless Devices in Telemedicine. Europe 5: 25 .
4. Bali S, Singh AJ (2007) Mobile phone consultation for community health care in rural north India. J Telemed Telecare 13: 421-424.

5. Ikhu-Omoregbe NA (2008) Journal of Health Informatics in Developing Countries.

6. Rohm BWT, Rohm Jr CET (2004) Evolving medical informatics: from diagnosis to prognosis. Int J Electron Healthc 1: 103-111.

7. Perera I (2009) Journal of Health Informatics in Developing Countries.

8. Braun R, Catalani C, Wimbush J, Israelski D (2013) Community Health Workers and Mobile Technology: A Systematic Review of the Literature. PLoS ONE 8: e65772.

9. Aranda-Jan (2014) Systematic review on what works, what does not work and why of implementation of mobile health ( $\mathrm{mHealth}$ ) projects in Africa. BMC Public Health 14: 188.

10. Chib A (2010) The Aceh Besar midwives with mobile phones project: Design and evaluation perspectives using the information and communication technologies for healthcare development model. J Comp Med Com 15: 500-525.

11. Campbell N, Schiffer E, Buxbaum A, McLean E, Perry C, et al. (2014) Taking knowledge for health the extra mile: participatory evaluation of a mobile phone intervention for community health workers in Malawi. Glob Health Sci Pract 2: 23-34.

12. Charles S (2014) Assessing the impact of mHealth interventions in low- and middle-income countries - what has been shown to work? Global Health Action 7: 25606.

13. Modi D, Gopalan R, Shah S, Venkatraman S, Desai G, et al. (2015) Development and formative evaluation of an innovative mHealth intervention for improving coverage of community-based maternal, newborn and child health services in rural areas of India. Glob Health Action 8: 26769.

14. Braun R, Catalani C, Wimbush J, Israelski D (2013) Community Health Workers and Mobile Technology: A Systematic Review of the Literature. PLoS ONE 8: e65772.

15. MacLeod B, Phillips J, Stone AE, Walji A, Awoonor-Williams JK (2012) The Architecture of a Software System for Supporting Community-based Primary Health Care with Mobile Technology: The Mobile Technology for Community Health $(\mathrm{MoTeCH})$ Initiative in Ghana. Online J Public Health Inform 4.

16. Braun R, Catalani C, Wimbush J, Israelski D (2013) Community Health Workers and Mobile Technology: A Systematic Review of the Literature. PLoS ONE 8: e65772.

17. http://www.jstor.org/stable/10.7864/j.ctt7zsvqt.9

18. Garai A (2011) Role of mHealth in rural health in India and opportunities for collaboration. Mobile Communication 2011: 1-5.

19. World Health Organization (2011) mHealth: New Horizons for Health through Mobile Technologies: Based on the Findings of the Second Global Survey on EHealth. Geneva 3: 1-112.

20. Piette JD, Lun KC, Moura LA, Fraser HSF, Mechael PN, et al. (2012) Impacts of e-health on the outcomes of care in low- and middle-income countries: Where do we go from here? Bull World Health Organ 90: 365-372 